\title{
The meteorology of the human body
}

A chy joints, according to folklore, point to the arrival of rain. It's a tale told by many an arthritic grandmother, but it also holds true in medicine. Weather can influence a variety of medical conditions, worsening symptoms and, in some cases, increasing the risk of death. But keeping track of weather patterns and their impact can be time-consuming and confusing for patients. MediClim, a new online service, hopes to take the guesswork out of weather-health management.

Dr. John Bart and meteorologist Denis Bourque have launched a free subscriber-based alert system that notifies users by email when their symptoms might be aggravated by upcoming weather conditions. The service aims to help people better manage their medical conditions. "We hope that forewarned is forearmed," says Bart.

MediClim (www.mediclim.com) tracks weather patterns and associates them with 5 medical conditions: arthritis, asthma, diabetes, heart disease and migraine. Subscribers provide a small amount of personal information, including their illness, postal code and email address, and receive alerts when the weather changes in such a way that it can cause a flare-up. Most people who sign up receive 2-4 warnings a month.

The service is currently available in Canada, the United States and the United Kingdom, but Bart says they hope to roll it out across Europe, beginning with France in April. They will continue to add conditions to the database as they collect more data.

"We wanted to provide people with the opportunity to understand that the environment is involved in their health and that they can do something about it," Bart says. Although not everybody is equally affected by weather, some may find the warnings informative. For example, a woman with arthritis may want to postpone a shopping trip to the mall if the weather suggests her symptoms may worsen over the next 24 hours.

MediClim is based on European research. "The Germans spent years studying weather maps and looking for the associations between weather and certain conditions," says Bourque. It

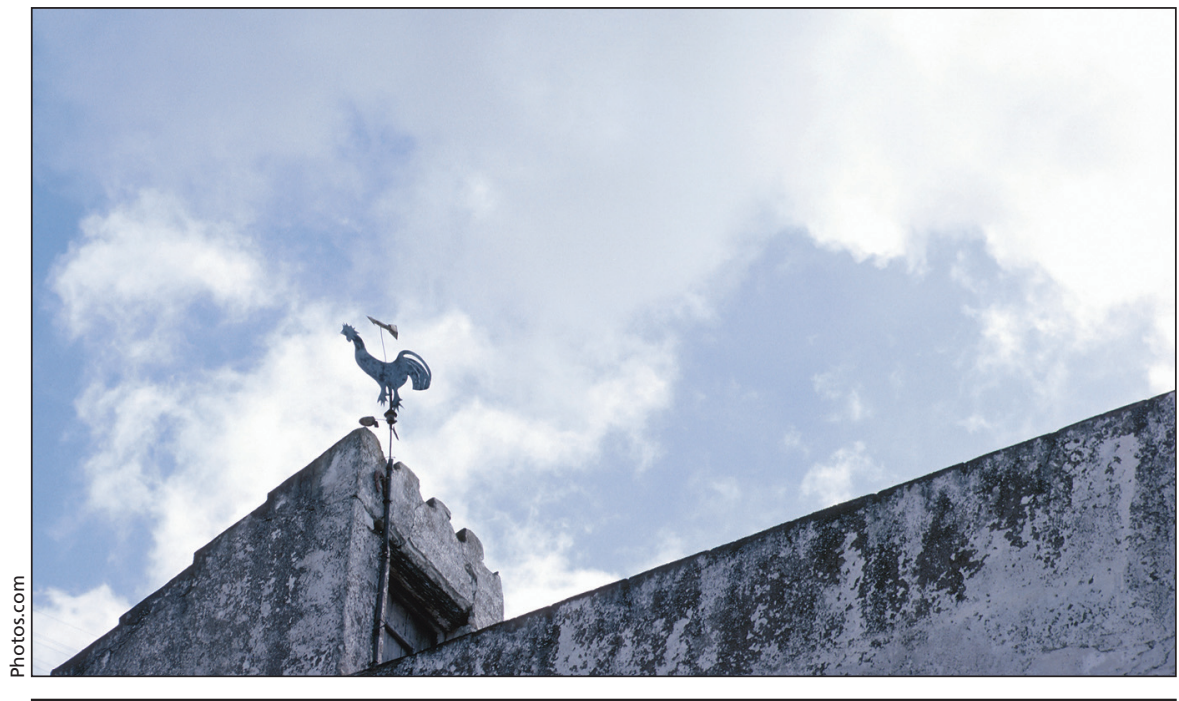

"Forewarned is forearmed," says Dr. John Bart of a new online alert system that will notify people with 5 medical conditions - arthritis, asthma, diabetes, heart disease and migraine - when their symptoms might be aggravated by weather conditions.

tracks temperature, humidity and barometric pressure at ground level, wind speed and direction at 2 different levels, over a 7-day period to produce 13 different categories - A through $\mathrm{L}$ - that show relationships with different conditions. (A 14th category, M, indicates that the pattern has no relationship with the condition.) The weather data come from databases at the US National Oceanic and Atmospheric Administration.

Although similar programs linking weather and health are already offered to the UK health care system and to the public in Germany, none offer personalized alerts.

Many people are unaware that weather can exacerbate their symptoms. "When I tell people this they're surprised," says Peter Liu, a cardiologist at the Peter Munk Cardiac Centre in Toronto, Ontario. He agrees that doctors and patients should be more tuned into their symptoms and the surrounding environment.

A drop in air temperature can cause bronchoconstriction in asthmatics, says Dr. Louis Jacques, a community medicine specialist at the Montreal Chest Institute in Montréal, Quebec. "They may need to take a puff [from their inhaler] before they go out, or they may try to prevent their exposure."

Headaches are tied to higher temper- atures and lower barometric air pressure. A recent study found that the risk of headache rose $7.5 \%$ for every $5^{\circ} \mathrm{C}$ increase in temperature (Neurology 2009; 72:922-7). The authors also found that when the barometric pressure dropped, individuals were more likely to visit the emergency department with a headache 48 to 72 hours later, although this association was less strong.

While it can be easy to understand how weather can exacerbate asthma, it's less clear to the public how weather influences heart disease and diabetes.

Liu cautions his patients - particularly the weekend warrior types who think they can still play hockey like teenagers - to tone down their physical activity when the temperature drops. "In the winter, in colder weather, blood pressure goes up 3 or 4 millimetres of mercury because the blood vessels constrict more," he says. "It makes the heart work harder."

Diabetes is less well understood. Bourque points to German scientific literature that shows that blood viscosity varies with the weather. "In a cold front, viscosity goes up," he says. In the long run, it means that people with diabetes could have more difficulty managing their blood sugar on certain days.

MediClim does not offer specific medical advice but urges subscribers to 
heed their doctor's advice as closely as possible on warning days. If it works, it could cut down on visits to the doctor and trips to the emergency room, freeing up overworked medical staff.

"It's an interesting idea and the concept is good," says Liu. "The only challenge is whether it is better than anything we already have."

Because MediClim does not track smog, it may not replace the importance of the smog alert system followed by patients with cardiovascular and respiratory conditions.

Gordon McBean, chair of policy at the Institute for Catastrophic Loss Reduction at the University of Western Ontario, says weather will increasingly play a role in patient management, especially as the climate continues to change. Warmer winters with increased snowfall could spell trouble for individuals with heart disease who decide to shovel their walks, and summer heat waves could make smog episodes more frequent. McBean, who has previously collaborated with Bourque and Bart, envisions an integrated natural hazards and warning system that would allow patients to plan their activities based on the weather. "People would learn how to self-adjust based on the levels. Some will know, for example, that a 4 is bad, where others will learn that 8 doesn't bother them at all." - Hannah Hoag, Montréal, Que.

DOI:10.1503/cmaj.090437

\section{Briefly}

Resident hours: The United States Accreditation Council for Graduate Medical Education has approved an 18-month review (www.acgme.org /acWebsite/home/nascaletter_feb2009 .pdf) of resident duty hour standards in light of an Institute of Medicine committee recommendation that "duty hours should not exceed 16 hours per shift unless an uninterrupted 5-hour break for sleep is provided within shifts that last up to 30 hours." The Institute's Committee on Optimizing Graduate Medical Trainee (Resident) Hours and Work Schedules to Improve

\section{More news @ www.cmaj.ca}

Ease of traffic: Calls are being made for a global health credentialing system that expedites physician migration. - Erin Driscoll, CMAJ

Dementia: The British government hopes to mitigate the effects of a forecast dementia crisis by opening memory clinics in every town and training general practitioners to spot early warning signs. Mary Helen Spooner, London, England

Hospital tracking: Radio frequency identification readers are becoming all the rage in United States health care facilities. - Milan Korcok, Fort Lauderdale, Florida, USA

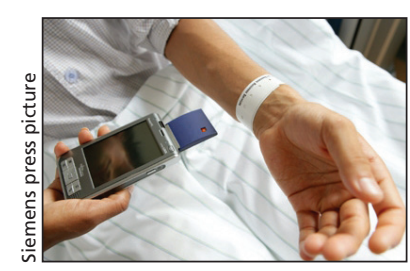

Dispatch: Amid the repetitive thumping of approaching helicopters, a Kingston, Ontario, physician admires the ingenuity of the Canadian-led

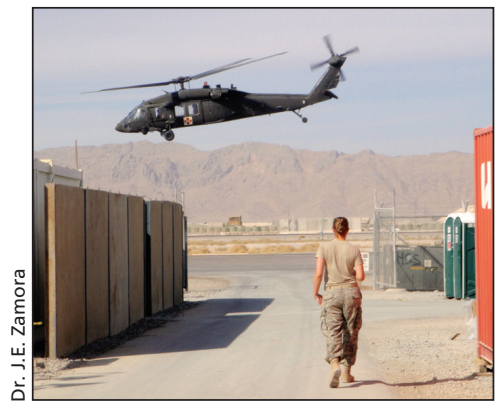
multinational medical unit in Khandahar, Afghanistan. - Jorge Enrique Zamora, MD, Khandahar, Afghanistan

Sachets: The manufacturer of an oral tobacco product now available in Sweden and Norway and parts of Canada claims it encourages harm reduction. Erika Gilbert, Ottawa, Ont.

DOI:10.1503/cmaj.090489

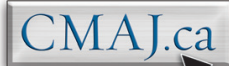

Patient Safety also recommended that an external independent body be created to provide oversight and enforcement of resident duty hours (www.iom.edu/Object .File/Master/60/469/residency\%20hours $\% 20$ revised $\% 20$ for $\% 20$ web.pdf).

Mobility: Doctors, nurses, pharmacists, paramedics and a host of other health professionals will obtain increased portability of their professional licences as of April 1 as a result of an amendment to the Agreement of Internal Trade reached by federal and provincial ministers of trade. The move will allow family doctors who are not certified by the College of Family Physicians of Canada and specialists not certified by the Royal College of Physicians and Surgeons of Canada, but who hold unrestricted licences within a province, to move to another jurisdiction.

FDA commissioner: United States President Barack Obama has appointed former New York City health commission Dr. Margaret "Peggy" Hamburg as the Food and Drug Administration's commissioner. Obama also indicated that his new administration will undertake a comprehensive review of FDA structure and operations. As well, he appointed a new Food Safety Working Group to advise him "on improving coordination throughout the government, examining and upgrading food safety laws, and enforcing laws that will keep the American people safe."

Sport supplements: The not-for-profit organization NSF International has launched an online initiative (www.nsfsport.com) aimed at providing athletes and coaches with a list of dietary supplements and sports nutrition products that can be safely used without violating international antidoping rules. Wayne Kondro, CMAJ

DOI:10.1503/cmaj.090484 